\title{
MEDICALIZAÇÃO NA INFÂNCIA EM TEMPOS DE CRISE PSÍQUICA
}

\author{
Júlia Abelin Ceccim Silvester ${ }^{1}$; Cristiane Bottoli ${ }^{2}$
}

\section{RESUMO}

O presente trabalho objetiva compreender os fatores que envolvem a medicalização na infância, para contribuir e incentivar as pesquisas no que se refere a esta temática e seus impactos, principalmente diante de um contexto como o da pandemia. A metodologia utilizada foi a revisão bibliográfica, que buscou refletir sobre os significados da medicalização na infância, em contextos relacionados a família, escola e momentos de crise, como a pandemia na atualidade. A partir do material revisado entende-se que no momento atual o medo de doenças futuras ou do aparecimento de algum transtorno, estimula a medicalização na infância, que, diante do poder da cultura médica atual, a capacidade das pessoas de lidar com seus sofrimentos parece estar diminuindo. Diante desta realidade é importante o estímulo a autonomia das crianças e suas famílias, para que cuidem de sua saúde, valorizando a capacidade de compreensão das questões que envolvem o sofrimento humano.

Palavras-chave: Desenvolvimento; Infância; Pandemia; Saúde mental.

\section{Eixo Temático: Atenção Integral e Promoção à Saúde (AIPS)}

\section{INTRODUÇÃO}

Atualmente, o conceito de medicalização tem sido abordado cada vez mais no campo das políticas públicas que envolvem a saúde, educação e a sociedade. Inúmeros debates sobre o aumento significativo do uso de medicamentos têm sido promovidos em torno dessa questão, outro ponto também muito discutido é o de que este aumento não diz mais respeito apenas aos adultos, mas também as crianças.

Com o objetivo de amenizar sintomas ou comportamentos indesejados, pais e também as escolas tentam, com medicamentos, corrigir e enquadrar as crianças em padrões convencionais de "normalidade". Com o início da pandemia da COVID-

\footnotetext{
${ }^{1}$ Autor/Apresentador - Universidade Franciscana, juceccim@hotmail.com.

2 Orientador - Universidade Franciscana, cbottoli@ufn.edu.br.
} 
19 as escolas tiveram que fechar as suas portas e consequentemente as famílias tiveram que se haver com demandas como a de achar meios para conseguir manter a saúde mental de suas crianças durante a quarentena, aqui, mais uma vez, a medicalização se torna uma saída rápida e eficaz, mas eficaz para que e para quem?

Sigal (2009) afirma que o ato de apagar rapidamente o que incomoda, configura-se na domesticação das crianças que não apresentam comportamentos que se alinham às nossas exigências. Tendo em vista os aspectos observados, este trabalho tem como objetivo geral compreender os fatores que envolvem a medicalização na infância em momentos de crise, buscando contribuir e incentivar as pesquisas no que se refere à medicalização da infância e seus impactos, principalmente em um contexto como o da pandemia.

\section{METODOLOGIA}

Este trabalho tem como abordagem metodológica uma pesquisa qualitativa, a qual busca através da pesquisa bibliográfica a coleta de informações, para identificar e alcançar os objetivos propostos. A escolha por essa metodologia se justifica porque, de acordo com Minayo (2003), a pesquisa qualitativa se propõe a responder questões, a partir de uma preocupação com um âmbito da realidade que não pode ser quantificável.

$\mathrm{Na}$ pesquisa bibliográfica foram consultadas várias literaturas relativas ao assunto em estudo, artigos publicados na internet e que possibilitaram que este trabalho tomasse forma para ser fundamentado. Segundo Marconi e Lakatos (1992), a pesquisa bibliográfica é o levantamento de toda a bibliografia já publicada, em forma de livros, revistas, publicações avulsas e imprensa escrita. A sua finalidade é fazer com que o pesquisador entre em contato direto com todo o material escrito sobre um determinado assunto, auxiliando o cientista na análise de suas pesquisas ou na manipulação de suas informações. Ela pode ser considerada como o primeiro passo de toda a pesquisa científica.

Desta forma, neste trabalho serão revisados conceitos relativos a medicalização na infância; família, escola e momentos de crise. 


\section{RESULTADOS E DISCUSSÕES}

\subsection{A MEDICALIZAÇÃO NA INFÂNCIA}

Tendo início na década de 1960, o conceito de medicalização é utilizado de forma recorrente e possui uma grande diversidade de compreensões. Sendo assim, para aprofundar esse debate, é indispensável compreender o percurso e as mudanças históricas desse conceito. Contudo, pode-se afirmar que muito antes, no século XVIII, o conceito de medicalização já se reproduzia, com o nascimento da medicina moderna e do movimento higienista. Ao final do século XX, percebe-se que o termo já não se restringia apenas ao campo da medicina, como resultado da disseminação da medicalização por autores não médicos (ZORNANELLI et al., 2014; GAUDENZI E ORTEGA, 2012).

Michel Focault, em seus estudos, no final da década de 1970, contribui para o debate a respeito da medicalização tratando-a como o motivo central do funcionamento do que se chamaria de nascimento da biopolítica, referindo-se às normatizações exercidas sobre a população. A medicalização está então ligada à uma medicina que vale-se do poder de seu discurso científico e toma a sociedade como objeto de higienização disciplinando corpos. A medicina então, amplia sua apropriação chegando ao biopoder, o poder sobre a vida das pessoas. No olhar Foucaultiano, o poder disciplinar estrutura-se em uma nova forma de olhar e falar sobre os corpos e seu funcionamento. Por meio dessa racionalidade científica surge saúde e doença, que passam a ser objeto da medicina. A doença torna-se um estado corporal, sendo assim, os sintomas assumem destaque e tornam-se os determinantes das doenças, representando, assim, um sinal de patologia e não uma tentativa de solução (FOCAULT, 2008).

Vale lembrar que a narrativa de Foucault vem de uma época anterior ao que os outros autores - mais contemporâneos - se dedicaram a dizer, com isso, em um contexto mais atual, um dos principais interlocutores a criar uma teoria sobre a medicalização é Ivan Illich, o qual acreditava na valorização e na autonomia do sujeito na forma de lidar com suas realidades de dores e doenças. No ponto de vista de Illich, a medicina impõe a medicalização para a sociedade, a qual, por sua vez, 
perde o seu poder de escolha diante do saber médico. O autor traz o conceito de iatrogenia, para justificar a existência de uma epidemia de doenças que são causadas pela medicina, tais como os efeitos colaterais de um tratamento médico. Entretanto, com a popularização da medicina, em especial a medicalização, essa prática acabou tornando-se parte da cultura popular, pois passamos a entender a necessidade da medicalização como como algo natural (ILLICH, 1975).

Mais ao fim do século XX, Peter Conrad, traz a ideia de que medicalizar é colocar o problema de saúde em um plano onde somente especialistas conseguirão debate-lo, devido a existência dos termos médicos, excluindo a população da discussão (CONRAD, 1992). Trazendo a medicalização na infância, especialmente em relação aos problemas a respeito da educação, ou melhor, das chamadas "doenças da não-aprendizagem", Collares e Moysés (1996) constataram que dentro do sistema educacional, todos, mesmo que de áreas diferentes, focam as causas do fracasso escolar nas crianças e em suas famílias. Assim, o sistema educacional acaba ficando em segundo plano quando se fala nos motivos que causam o fracasso escolar e a medicalização surge como uma alternativa para solucionar esses problemas.

Entendendo que a medicalização transforma modos de existir em patologias, Silva, Schafer e Bonfiglio (2013) manifestam o quanto as crianças já chegam medicadas para os atendimentos psicoterapêuticos, fazendo com que a medicação apareça como solução imediata para os problemas. Sigal (2009) afirma que o atualmente a medicação prevalece à análise da relação com o outro, à elaboração e à construção do sujeito, tornando-se um atalho para amenizar as angústias. Seguindo seu raciocínio, a autora afirma que 0 ato de silenciar rapidamente o que incomoda representa a domesticação das crianças que não apresentam comportamentos que se alinham com as exigências sobre à infância.

Dessa maneira, Perozin (2005) relata que os remédios são interferências nas formas de comportamento, cognição, percepção e afetividade das crianças. Sendo importante também relembrar que tudo na infância é um aprendizado, portanto aqui, o desejo dos pais e professores de terem crianças perfeitas não pode se tornar uma doença. Associado a isso, Perozin (2005) traz que na época atual 
existem poucas informações sobre o impacto dos psicofármacos à longo prazo em um cérebro ainda em desenvolvimento, temendo, assim, que causem alterações químicas, o que consequentemente ocasionaria mudanças nas emoções, sentidos e comportamento das crianças.

A saúde pública, especialmente no início do século $X X$, caracterizou-se, com o modelo higienista, pelas práticas de controle dos ambientes e dos indivíduos. Esse modelo voltou-se para o controle social, surgindo então bases para justificar os padrões de normalidade exigidos, servindo de apoio para a medicalização.

Devido à procura de pais, professores e médicos pela criança perfeita, ou seja, aquela que se comporta, que é atenta e que corresponde às expectativas sociais sobre a infância, no decorrer dos anos houve um aumento significativo na busca por algum medicamento que estabelecesse uma normatização, silenciando esta criança, retirando sua autonomia e subjetividade.

\subsection{FAMÍLIA, ESCOLA E MOMENTOS DE CRISE}

A palavra "crise", segundo Parada (2004) pode ser definida como um estado de desequilíbrio emocional do qual uma pessoa que se vê incapaz de sair com os recursos de afrontamento que habitualmente costuma empregar em situações que a afetam emocionalmente. O estado de crise é limitado no tempo, quase sempre se manifestando por um evento desencadeador, e sua resolução final depende de fatores como a gravidade do evento e dos recursos pessoais e sociais da pessoa afetada (MORENO et al., 2003).

Sendo assim, vale destacar que o fenômeno de crise se diferencia em duas partes, as crises evolutivas e as crises circunstanciais. As crises evolutivas dizem respeito à realização não satisfatória das passagens do desenvolvimento do indivíduo. Elas podem e costumam ser previsíveis, já que as etapas do crescimento e os momentos decisivos em cada uma delas são conhecidas e ocorrem com a maioria das pessoas, são situações criadas internamente, tais como mudanças fisiológicas e cognitivas, tais como, a infância, adolescência, o envelhecimento e a morte, as quais podem desencadear ou não uma resposta de crise (SLAIKEU, 1996; WAINRIB \& BLOCH, 2000). Já as crises circunstanciais são resultantes de situações 
encontradas no ambiente, costumando surgir em consequência de eventos os quais o indivíduo não consegue prever ou controlar, como a morte repentina de um ente querido, doenças, desastres naturais, entre outros. No contexto de crise circunstancial, podemos trazer como um exemplo atual, a pandemia da COVID-19, a qual devido sua emergência, levou as famílias ao confinamento domiciliar e trouxe um contexto de mal-estar geral, afetando, de forma particular, as crianças.

Liria e Veja (2002) consideram que o fim de uma crise pode pôr em risco a saúde mental ou ser um ponto inicial para mudanças que possibilitem um funcionamento melhor do que o anterior ao desencadeamento do evento. Dessa maneira, quando a crise é resolvida satisfatoriamente, ela pode auxiliar o desenvolvimento do indivíduo, caso contrário, poderá tornar-se em um risco, aumentando a suscetibilidade da pessoa para transtornos mentais. O indivíduo pode apresentar sinais e sintomas clínicos em resposta ao estado provocado pela crise, acabando assim, necessitando de alguma intervenção medicamentosa para a sua solução.

Lewis, Dlugokinski e Caputo (1988) consideram que a família e a rede social a qual a criança pertence, podem ser possíveis fontes de risco para 0 desenvolvimento de desordens emocionais, mas também podem ser recursos que devem ser estimulados a realizar a promoção de um desenvolvimento psicossocial saudável.

De fato, Patto (2000) entende que na produtividade, principalmente escolar, da criança, existe a interferência de conflitos psíquicos vivenciados por ela, sejam eles decorrentes de sua família ou não. Contudo, afirma que não se pode deixar de considerar que as relações que a escola estabelece com o aluno e sua subjetividade contribuem, modificam ou reforçam quaisquer que sejam esses conflitos.

Segundo Souza (1997), grande parte dos professores faz uso do encaminhamento psicológico e médico como uma alternativa para não se depararem com os conflitos de seus alunos, o que leva a questionar as características de formação de professores e especialistas em educação. Conforme a autora, o encaminhamento de uma criança para o psicólogo em função de um problema de aprendizagem ou de comportamento, traz implícita uma relação de causa e efeito 
EDUCAÇÃO, SAÚDE

ETECNOLOGIA

26 A 28 DE OUTUBRO DE 2021

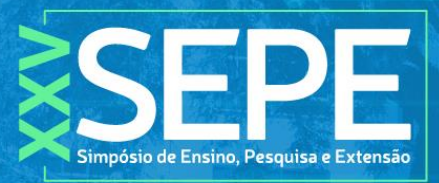

TRABALHO COMPIETO

que ainda não está comprovada. Muitas vezes a escola rotula como doença ou incapacidade, culpabiliza e estigmatiza alguns alunos por um fracasso que não é só seu.

Conforme Graminha (1994), devido à um estado contínuo de mudanças e desenvolvimento, existe uma grande dificuldade em decidir quando uma criança está realmente apresentando "distúrbio emocional" e precisando ajuda de um profissional devido às questões de desenvolvimento que englobam essa etapa da vida. Sendo assim, para a autora, um comportamento infantil pode ser considerado distúrbio em uma determinada idade e estar dentro dos limites da "normalidade" em outra, levando-nos a pensar sobre a real necessidade de identificar quando se faz indispensável a busca por um atendimento psicológico ou psiquiátrico, trazendo assim também, a importância da compreensão sobre o infantil, a infância e o que é esperado de cada fase do seu desenvolvimento, tanto no quesito de rendimento escolar, como nas relações sociais por ela estabelecidas.

O acesso facilitado aos diagnósticos de transtornos psicológicos, tais como o TDAH, publicado no DSM- IV e, posteriormente, no DSM-5, faz com que os professores e os próprios pais identifiquem tal transtorno através de sintomas como o de desatenção, hiperatividade, impulsividade e encaminhem as crianças para que recebam um tratamento medicamentoso, visto que este tipo de tratamento está difundido como solução para o problema. Para Hacking (2000) o diagnóstico pode ser decisivo para a vida do sujeito, principalmente, quando ele é enquadrado numa classificação psiquiátrica, a qual denomina seu lugar no contexto social. A partir do momento em que o sujeito aceita as classificações que lhe são definidas, seu comportamento vai se moldando conforme as descrições estabelecidas para quem recebe tal rótulo. As pessoas que convivem no mesmo contexto (familiares, amigos, colegas) passam a se relacionar com este sujeito considerando sua classificação e mantêm a expectativa de cura.

Para Caponi (2007), a patologização do sofrimento e a consequente medicalização dos comportamentos considerados inadequados, parecem se destacar em uma época a qual dita um estado de bem estar e promove a intolerância ao sofrimento próprio e alheio. A primeira questão em relação aos 
sintomas tidos como anormais, é como se pode ter a medida exata para estabelecer o comportamento de cada criança, por exemplo, "inquietação, incapacidade de permanecer sentado", bem como conhecer a dinâmica familiar de cada uma, pois há aspectos diretamente relacionados à educação e às relações familiares, que implicam no modo de ser da criança (APA, 2013).

Os pais encontram na medicação para seus filhos e nos resultados imediatos obtidos pelo uso de medicamentos, um alívio para o sofrimento daquela família. Benevides (2015) considera a existência daquilo que chama de "indústria de normalização da infância", indústria essa que começa convencendo os pais e introduzindo neles a crença de que não sabem cuidar de suas crianças, causando um estado de incerteza nas suas capacidades enquanto provedores do bem-estar de seus filhos, fazendo com que, desta forma, as funções dos pais fiquem atravessadas pelo saber médico. O uso de medicamentos acaba assim como uma saída viável e eficaz para enquadrar as crianças nas exigências das escolas e diminuir, quase que silenciando, o sofrimento e angústia das famílias diante do não saber como lidar com suas crianças.

\section{CONCLUSÃO}

A medicalização é um processo que trata como legítimas as intervenções preventivas para questões sociais mais amplas. Relacionando esse assunto com as dificuldades escolares das crianças, entende-se que o processo de medicalizar tenta parar os sintomas sem levar em consideração as manifestações singulares e complexas de cada sujeito. Portanto, em vez de analisar e ponderar que as crianças estão com seu psiquismo em formação, presume-se que ela possui um déficit neurológico. Às vezes, deve-se considerar que os sintomas podem não ser um sinal de doença, mas sim uma tentativa de solução, aparecendo como uma maneira singular na busca por uma resposta as suas dificuldades.

O estudo analisou tratamentos com medicamentos para diferentes manifestações de dor de vida, ao usar psicofármacos a criança é privada do tempo necessário para superar o abalo de uma morte importante, uma doença ou um acidente grave, e assim estabelecer uma nova referência proporcional à perda ou 
sofrimento que vivenciou. Na cultura medicalizante atual, o medo de doenças futuras ou do aparecimento de algum transtorno, seja por um acontecimento ou comportamento, estimula a medicalização expandindo seu campo de atuação, sendo assim, diante do poder da cultura médica atual, a capacidade das pessoas de lidar com seus sofrimentos parece estar diminuindo.

Não se trata de menosprezar os benefícios que os medicamentos trazem à vida das pessoas, mas sim de lembra-las a importância de sua autonomia para que cuidem de suas vidas e sua saúde, é importante valorizar a capacidade das pessoas de compreender melhor suas questões de sofrimento e participar ativamente do seu plano terapêutico, para que consigam, junto do profissional, usufruir melhor dos tratamentos disponíveis. Não há um significado único para reivindicar ou negar um diagnóstico na contemporaneidade. Gerenciar essa complexa questão no cotidiano dos serviços de saúde é um desafio para seus profissionais.

De acordo com Tesser (2009), devido à pressão das escolas, horários de consultas, pacientes e seus familiares e expectativas de medicamentos e serviços de saúde que aliviam sua dor, os profissionais às vezes se sentem vencidos pelo processo influente que é o de medicalização, por isso, relembramos que o encontro com o profissional de saúde, juntamente com o seu tratamento, deve ser feito de forma humanizada, entendendo que o paciente fala melhor do que ninguém sobre si mesmo, para que assim consigam construir um plano de tratamento efetivo e significativo na vida do sujeito.

Espera-se que as escolas, juntamente com os pais, consigam assumir cada vez mais o papel de educar as crianças, tornando-se um espaço de abertura de novos valores, trazendo às crianças novos ideiais, bem como informações importantes para o seu crescimento e convívio social. A escola ocupa muitas horas do dia das crianças e também desempenha papel fundamental na vida dos seus alunos durante anos, por isso deve ser um ambiente acolhedor, transformador e formativo, onde os conflitos pessoais das crianças possam ser discutidos juntamente com a família, sem a necessidade do uso de medicamentos como prioridade no tratamento da vida da criança. 


\section{REFERÊNCIAS}

APA - American Psychiatric Association. Diagnostic and Statistical Manual of Mental Disorders, Fifth Edition (DSM-5). Arlington, VA: American Psychiatric Association, 2013.

BENEVIDES, P. S. Governar através das crianças: notas sobre a indústria de normalização pela infância. In: DANTAS, J. B. (Org.) A infância medicalizada: discursos, práticas e saberes para o enfretamento da medicalização da vida. 1 ed. Curitiba, PR:CRV, p. 35-48, 2015.

CAPONI, S. "Viejos y nuevos riesgos: en busca de otras protecciones". Cadernos de Saúde Pública, v. 23, n. 1, p. 7-15, 2007.

COLLARES, C. A. L.; MOYSÉS, M. A. A. Preconceitos no cotidiano escolar, ensino e medicalização. São Paulo, Cortez / FE-FCM-UNICAMP, 1996.

CONRAD, P. Medicalization and Social Control. Annual Review of Sociology, Palo Alto, v. 18, p. 209-232, 1992.

FOUCAULT, M. O Nascimento da biopolítica. São Paulo: Martins Fontes, 2008.

GAUDENZI, P.; ORTEGA, F. O estatuto da medicalização e as interpretações de Ivan Illich e Michel Foucault como ferramentas conceituais para o estudo da desmedicalização. Interface - Comunicação, Saúde, Educação, 16(40), p. 21-34, 2012. Disponível em: https://dx.doi.org/10.1590/S1414-32832012005000020 Acesso em: 05/06/2021

GRAMINHA, S.S.V. Problemas emocionais/comportamentais em uma amostra de escolares: incidência em função do sexo e idade. Revista Psico. Porto Alegre. 25(1): 49-74. jan/jun, 1994.

HACKING, I. Múltipla personalidade e as ciências da memória. Rio de Janeiro: José Olympio, 2000.

ILLICH, I. A expropriação da saúde: nêmesis da medicina. Ed. Nova Fronteira, São Paulo, 1975.

LAKATOS, E. M.; MARCONI, M. de A. Metodologia do trabalho científico: projetos de pesquisa/pesquisa bibliográfica/teses de doutorado, dissertações de mestrado, trabalhos de conclusão de curso. 8. ed. São Paulo: Atlas, 2017.

LEWIS, R. J.; DUGLOKINSKI, E. L.; CAPUTO, L. M.; GRIFFIN, R. B. Children at risk for emotional disorders: Risk and resources dimensions. Clinical Psychology Review, 8, 417-440, 1988. 
LIRIA, A. F.; VEJA, B. R. Intervención en Crisis. Madrid: Editorial Sintesis. 2002.

MINAYO, M. C. de S. (Org). Pesquisa social: teoria, método e criatividade. Rio de Janeiro: Vozes, 2003.

MORENO, R. R.; PEÑACOBA, C. P.; GONZÁlEZ-GUTIÉRREZ, J. L.; ARDOY, J. C. Intervención Psicológica en Situaciones de crisis y emergencias. Madrid: Dykinson. 2003.

PARADA, E. Psicologia Comportamental Aplicada al Socorrismo Profesional. Primeros Auxilios Psicologicos. 2004. Recuperado em 02 de janeiro de 2008 do site Escuela Segoviana de Socorrismo: http://members.fortunecity.es/esss1/Jornadas97ParadaE.htm

PATTO, M. H. S. A produção do fracasso escolar: histórias de submissão e rebeldia. São Paulo: Casa do Psicólogo, 2000.

PEROZIN, L. O ministério da sensatez adverte: nenhum remédio educa. Revista Educação, São Paulo, ano 9, n. 104, 2005.

SIGAL, A. M. Desatenção na infância: um estudo sobre a síndrome de desatenção (ADD). In: Casa do Psicólogo, p. 307-321, 2009.

Escritos metapsicológicos e clínicos. São Paulo:

SILVA, J.C.; SCHÄFER, C.; BONFIGLIO, M.S. A medicalização da infância e o processo psicoterápico. Barbaroi, 39, dez. Santa Cruz, 2013.

SLAIKEU, K. A. Intervención en Crisis: manual para práctica e investigación. El Manual Moderno, México, 1996.

SOUZA, M.P.R. A queixa escolar e o predomínio de uma visão de mundo. In: Psicologia escolar: em busca de novos rumos. São Paulo: Casa do Psicólogo. 1997.

TESSER, C. (Org.) Medicalização social e atenção à saúdo no SUS. São Paulo: Hucitec, 2009.

WAINRIB, B. R.; BLOCH, E. L. Intervención en crisis y respuesta al trauma: teoría y práctica. Bilbao: Desclée de Brouwer. 2000.

ZORZANELLI, R. T.; ORTEGA, F.; BEZERRA JÚNIOR, B. Um panorama sobre as variações em torno do conceito de medicalização entre 1950-2010. Ciência e Saúde Coletiva, 19(6), 1859-1868, 2014. Disponível em: https://dx.doi.org/10.1590/1413-81232014196.03612013 Acesso em: 04/06/2021 